\title{
Prevalence and risk factor analysis for postpartum depression: a cross sectional study at tertiary care center, Mangalore
}

\author{
Vatsala Kamath, Disha Ajila, Shashirekha H. D.*
}

Department of Obstetrics and Gynaecology, A J Institute of Medical Sciences and Research Centre, Mangalore, Karnataka, India

Received: 17 December 2020

Accepted: 18 January 2021

\section{*Correspondence:}

Dr. Shashirekha H. D.,

E-mail: shashirekha685@gmail.com

Copyright: ( $)$ the author(s), publisher and licensee Medip Academy. This is an open-access article distributed under the terms of the Creative Commons Attribution Non-Commercial License, which permits unrestricted non-commercial use, distribution, and reproduction in any medium, provided the original work is properly cited.

\begin{abstract}
Background: The overall pooled estimate of the prevalence of Postpartum depression in Indian mothers is $22 \%$. In India, women who deliver at a health facility often stays less than $48 \mathrm{hrs}$ after delivery and this leaves little opportunity for health personnel to counsel the mother and family members on the signs and symptoms of Postpartum depression (PPD) and when to seek care. So, it is important to screen the postpartum woman for depression. Edinburgh Postnatal Depression Scale is used as an effective tool to assess the level of postnatal depression. The objective of the study was to assess the prevalence and risk factors associated with postpartum depression in the postnatal mothers using EDPS scale.

Methods: This study was conducted at A. J. Institute of Medical Sciences and Research Center from January 2019 to May 2020. A total of 950 postnatal mothers were interviewed using Edinburgh Postnatal Depression Scale.

Results: A total of 950 cases were studied. Prevalence of Postpartum depression was $15.78 \%$. Increased incidence was seen in the primigravida (12.2\%) compared to multigravidas (3.57\%). This study showed $1.89 \%$ mothers belonging to upper middle class, $5.05 \%$ belonging to lower middle class had PPD and $7.26 \%$ belonging to upper lower class and $1.57 \%$ patients belonging to lower class had PPD. In our study, $9.26 \%$ patients who underwent normal vaginal delivery had PPD and $6.52 \%$ of patients who underwent lower segment caesarean section had PPD. In the present study, it was found that $1.05 \%$ mothers having IUD babies and 5.2\% (96/950) mothers who required NICU admission developed PPD.

Conclusions: In this study, the prevalence of postpartum depression was $15.78 \%$. Risk of PPD is more with primigravida, belonging to lower middle class status, mothers who had NVD and mothers of IUD babies. Postpartum depression screening should be an integral part of postnatal care using EPDS scale. A multidisciplinary approach including obstetrician and psychiatrists and counsellor can jointly take care of the depressed mothers. Early screening of the women may reduce the adverse outcomes among both mother and child. Proper counselling should be done to all the pregnant women and the family members for the birth preparedness.
\end{abstract}

Keywords: EDPS scale, Postpartum depression, Prevalence

\section{INTRODUCTION}

The overall pooled estimate of the prevalence of postpartum depression in Indian mothers is $22 \% .^{1}$ The global prevalence of postpartum depression has been estimated as 100-150/1000 births. ${ }^{4}$
Postpartum depression can predispose to chronic or recurrent depression, which may affect the mother-infant relationship and child growth development. ${ }^{1}$ Although facility based deliveries are increasing in many low and middle income countries, a high proportion of pregnant mothers deliver at home. ${ }^{2}$ 
In India, women who deliver at a health facility often stay less than 48hrs after delivery and this leaves little opportunity for health personnel to counsel the mother and family members on the signs and symptoms of postpartum depression and when to seek care. ${ }^{3}$

Furthermore, mothers may be reluctant to admit their suffering either because of social taboos associated with depression or concerns about being labelled as a mother who failed to deliver the responsibilities of child care. ${ }^{1}$

While postpartum depression is a considerable health issue for many women, the disorder often remains undiagnosed and hence untreated. ${ }^{14,15}$

Certain studies shows that risk factors for postpartum depression are financial difficulties, marital conflict, lack of support from the family, past history of psychiatric illness, high parity, complications during pregnancy and low maternal education. ${ }^{10,11}$

Children of mothers with postpartum depression have greater cognitive, behavioural and interpersonal problems compared with the children of nondepressed mothers. ${ }^{12,13}$

Symptoms of postpartum depression may vary from postpartum blues to postpartum psychosis.

\section{Puerperal blues}

It is a transient state of mental illness observed 4-5days after delivery and it lasts for a few days. ${ }^{21}$

Nearly $50 \%$ of women suffer from the problem

Manifestations are depression, anxiety, tearfulness, insomnia, helplessness and negative feeling towards the infant. $^{21}$

\section{Postpartum depression}

It is observed in $10-20 \%$ of mothers.

It is more gradual in onset over 4-6monts following delivery or abortion. ${ }^{21}$

Change in the hypothalamopituitary adrenal axis may be a cause.

Manifested by loss of energy and appetite, insomnia, social withdrawal, irritability and even suicidal attitude. ${ }^{21}$

\section{Postpartum psychosis}

Observed in about $0.14-0.26 \%$ of mothers.

Onset is relatively sudden usually within 4 days of delivery.
Manifested by fear, restlessness, confusion followed by hallucinations, delusions, and disorientation.

Suicidal, infanticidal impulses may be present. $^{21}$

The objective of the study-was to assess the prevalence and risk factors associated with postpartum depression in the post-natal mothers using EDPS scale.

\section{METHODS}

The present study for assessment of postnatal depression was carried out in the Department of Obstetrics and Gynaecology, A.J Institute of Medical Sciences, Mangalore.

This is a cross sectional study conducted from January 2019 to May 2020. Institution ethical committee was approved for the study protocol.

A total of 950 postnatal mothers in their $3^{\text {rd }}-7^{\text {th }}$ postpartum period were assessed using Edinburgh Postnatal Depression Scale (EPDS).

The 10-question Edinburgh Postnatal Depression Scale (EPDS) is a valuable and efficient way of identifying patients at risk for perinatal depression. Mothers who score above 13 are likely to be suffering from a depressive illness of varying severity. A careful clinical assessment was carried out to confirm the diagnosis. This scale indicates how the mother has felt during the previous week. Written informed consent was taken from all the patients.

\section{Inclusion criteria}

Post-natal mothers who were willing to participate in the study are included in the study group.

\section{Exclusion criteria}

If mother is having past history of psychiatry illness and is already on anti-depressant and anti-anxiety medication are excluded from the study.

\section{RESULTS}

Out of 956 patients, 4 patients were excluded because they were on antipsychiatry medications, and 2 patients were not willing to participate in the study.

Data was entered in Microsoft excel sheet systematically. Categorical data was analysed. Statistics was taken out in percentages for all the variables.

Out of 950 population of postnatal women, $66.94 \%$ $(636 / 950)$ were between the age group of 19-25years and $33.05 \%$ (314/950) between the age group of 26-35years. In the present sample, 59.3\% (564/950) were 
primigravida and $40.63 \%$ (386/950) were multigravida. (Table 1).

Table 1: Distribution of the patients based on sociodemographic factors.

\begin{tabular}{|lll|}
\hline \multicolumn{2}{|l|}{ No. of cases } & Percentage \\
\hline Age & & \\
\hline 18-25 years & 636 & 66.94 \\
\hline 26-35 years & 314 & 33.05 \\
\hline Parity & \\
\hline Primigravida & 564 & 59.3 \\
\hline Multigravida & 386 & 40.63 \\
\hline Type of family & & \\
\hline Nuclear & 525 & 55.26 \\
\hline Joint & 425 & 44.73 \\
\hline Education & & \\
\hline Primary school & 370 & 38.94 \\
\hline High school & 250 & 26.31 \\
\hline Graduate & 295 & 31.05 \\
\hline Postgraduate & 35 & 3.5 \\
\hline Socioeconomic status & \\
\hline Upper middle & 168 & 17 \\
\hline Lower middle & 465 & 48.94 \\
\hline Upper lower & 246 & 25.89 \\
\hline Lower & 71 & 7.41 \\
\hline Mode of delivery & & 61.4 \\
\hline NVD & 584 & 38.52 \\
\hline LSCS & 366 & \\
\hline
\end{tabular}

In the present study, 38.94\% (370/950) patients studied till primary school, $26.31 \%$ (250/950) studied till high school, $31.05 \%$ (295/950) had completed their graduation and $3.5 \%(35 / 950)$ had completed their postgraduation (Table 1).

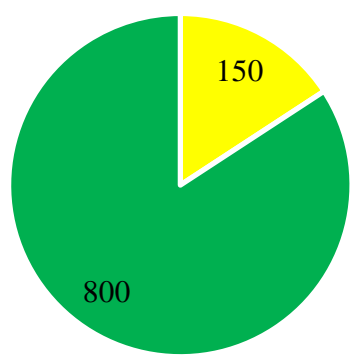

PPD PRESENT - PPD ABSENT

Figure 1: Prevalence of the study.

A total $17 \%$ (168/950) of the population were belonging to upper middle class and $48.94 \%$ (465/950) were belonging to lower middle class, $25.89 \%$ (246/950) were belonging to upper lower class and $7.41 \%$ (71/950) belonged to lower class (Table 1).
In this present study, 61.4\% (584/950) underwent normal vaginal delivery (NVD) and $38.52 \%$ (366/950) underwent lower segment caesarean section. (Table 1)

Out of 950 women included in study, 150 (15.78\%) women were found to have postpartum depression according to EDPS scale. (Figure 1)

This study showed $12 \%$ (18/150) mothers belonging to upper middle class, 32\% (48/150) belonging to lower middle class and $46 \%(69 / 150)$ belonging to upper lower class and $10 \%(15 / 150)$ patients belonging to lower class had PPD. (Table 2)

Table 2: Based on socioeconomic status.

\begin{tabular}{|lll|}
\hline Socioeconomic status & No. of cases & Percentage \\
\hline Upper middle & 18 & 1.89 \\
\hline Lower middle & 48 & 5.05 \\
\hline Upper lower & 69 & 7.26 \\
\hline Lower & 15 & 1.57 \\
\hline
\end{tabular}

Increased incidence of postpartum depression was seen in primigravida $77.33 \% \quad(116 / 150)$ compared to multigravida $22.66 \%$ (34/150). (Table 3)

Table 3: Based on parity.

\begin{tabular}{|lll|}
\hline & No. of cases & Percentage \\
\hline Primigravida & 116 & 12.2 \\
\hline Multigravida & 34 & 3.57 \\
\hline
\end{tabular}

In our study, $15.06 \%$ patients who underwent normal vaginal delivery (88/584) had PPD and $16.93 \%$ of patients who underwent lower segment caesarean section had PPD (62/366). (Table 4)

Table 4: Based on mode of delivery.

\begin{tabular}{|lll|}
\hline Mode of delivery & No. of cases & Percentage \\
\hline NVD & 88 & 15.06 \\
\hline LSCS & 62 & 16.93 \\
\hline
\end{tabular}

Out of 150 women who had PPD, 29.33\% (44/150) mothers who had baby mother side had PPD, $6.66 \%$ (10/150) mothers who had IUD babies developed PPD and $64 \%$ mothers $(96 / 150)$, whose babies were in NICU had PPD. (Table 5). This has been correlated with many other studies.

Table 5: Based on perinatal outcomes.

\begin{tabular}{|lll|}
\hline Perinatal outcomes & No. of cases & Percentage \\
\hline Mother side & 44 & 4.63 \\
\hline IUD & 10 & 1.05 \\
\hline NICU admission & 96 & 10.10 \\
\hline
\end{tabular}




\section{DISCUSSION}

Our study showed prevalence of PPD of $15.78 \%$ and it was supported by studies conducted by Patel et al and Hegde $\mathrm{S}$ et al who also concluded that in their studies that incidence of PPD was $11-16 \% .^{9,20}$

This study showed that there is increased incidence of postpartum depression in primigravida $(77.33 \%$ more compared to multigravidas $(22.66 \%)$. This was supported by study conducted by Blackmore et al and Kruthika $\mathrm{K}$ et al, who concluded in their study primiparity to be associated to be associated with PPD. ${ }^{5,19}$

Our study showed that there is increased incidence of postpartum depression in upper lower class (46\%) when compared to upper middle class (32\%), and this study was supported by study conducted by Abel Fekadu et al, showed that low socioeconomic status was the significant contributing factor for development of postpartum depression. ${ }^{16}$

Our study did not show any association between the literacy rate and risk of developing PPD, However, the other study conducted by Shafi et al, showed that there is decreased rate of PPD among graduates and among post graduates and it could be because of their self- esteem and better interpersonal relationship. Women from urban area are having more independent life and better life style choices, could act as a protective factor from mood disturbances during pregnancy. ${ }^{7}$

In our study, $15.06 \%$ patients who underwent normal vaginal delivery had PPD and $16.93 \%$ of patients who underwent lower segment caesarean section had PPD. Our study showed increased incidence of PPD in patients who underwent LSCS similar to the study conducted by Shafi AM et al, in which emergency lower segment caesarean section was the significant risk factor for development of PPD. ${ }^{7}$

It is found that, in our study out of 150 mothers who developed PPD, 10 mothers with IUD babies developed postpartum depression and 96 mothers whose babies are having NICU admission developed postpartum depression, and 44 mothers developed PPD who had baby mother side and the studies conducted by Rahul Mathur et al, Kanchana Rani et al and Azad R et al, have also showed same results that there is increased incidence of PPD in mothers having adverse perinatal outcomes. ${ }^{8,17}$, 18

For all 150 mothers who had PPD, appropriate referrals were given to the department of Psychiatry and with reassurance, counselling and psychoeducation, they improved. No pharmacotherapy was required in 149 patients.

One patient out of the 150 patients, went on to develop Insomnia, low mood, anhedonia, anergia, suicidal ideations, homicidal tendencies towards the babies (twins), neglect towards self and the babies, crying spells, refusal to eat- $7^{\text {th }}$ day postpartum. A referral was given to the department of psychiatry and the patient was diagnosed as having severe postpartum depression with possible psychotic symptoms. She was started on the atypical antipsychotic, olanzapine to help improve her insomnia and aggressive behaviour with a plan to aid antidepressants. The patient's insomnia and aggressive tendencies improved;

However the patient was discharged on request and was later lost to follow up.

\section{CONCLUSION}

In this study, the prevalence of postpartum depression was $15 \%$. Risk of PPD is more with primigravida, mothers belonging to lower middle class status, mothers who underwent lower segment caesarean section and mothers of IUD babies. Postpartum depression screening should be an integral part of postnatal care using EPDS scale. A multidisciplinary approach including obstetrician and psychiatrists can jointly take care of the depressed mothers. Early screening of the women may reduce the adverse outcomes among both mother and child. Proper counselling should be done to all the pregnant women and the family members for the birth preparedness.

Funding: No funding sources

Conflict of interest: None declared

Ethical approval: The study was approved by the Institutional Ethics Committee

\section{REFERENCES}

1. Upadhyay RP, Chowdhury R, Salehi A, Sarkar K, Singh SK, Sinha B, et al. Post partum depression in India:A systematic review and metanalysis. Bulletin of the World Health Organization. 2017;95:706-17C.

2. Joseph G, da Silva IC, Wehrmeister FC, Barros AJ, Victora CG. Inequalities in the coverage of place of delivery and skilled birth attendance: analyses of cross-sectional surveys in 80 low and middle-income countries. Reprod Health. 2016;13(1):77.

3. Home based newborn care operational guidelines (revised 2014). New Delhi: Ministry of Health and Family welfare; 2014. Available at; http://nhm.gov.in/images/pdf/programmes/childhealth/guidelines/Revised_Home_Based_New_Born _Care.

4. O'hara MW, Swain AM. Rates and risk of postpartum depression -a meta-analysis. Int Rev Psychiatr. 1996;8(1):37-54.

5. Blackmore ER, Jones I, Doshi M, Haque S, Holder $\mathrm{R}$, Brockington I, et al. Obstetric variables associated with bipolar affective puerperal psychosis. $\mathrm{Br} \mathrm{J}$ Psych. 2006;188:32-6.

6. Mayberry LH, Horowitz JA, Declercq E. Depression symptom prevalence and demographic risk factors 
among U.S. women during the first 2 years postpartum. J Obstet Gynecol Neonatal Nurs. 2007;36:542-9.

7. Afiya M.Shafi, Rohi Jain, Smita Pandey. A preliminary study on identifying specific risk factors of post partum depression. Int $\mathbf{J}$ Reprod Contracept Obstet Gynecol 2020;9(1):48-55.

8. Mathur P, Mathur R, Singh A. A clinical study of postpartum depression and its association with postnatal factors. Int $\mathrm{J}$ Reprod Contracept Obstet Gynecol. 2018;7:2120-2.

9. Patel V, Abas M, Broadhead J, Todd C, Reeler A. Depression in developing countries: lessons from Zimbabwe, BMJ. 2001;322:482-4.

10. Gelaye B, Rondon MB, Araya R, Williams MA. Epidemiology of maternal depression, risk factors, and child outcomes in low-income and middleincome countries. Lancet Psychiatr. 2016;3(10):97382.

11. Shidhaye P, Giri P. Maternal depression: a hidden burden in developing countries. Ann Med Health Sci Res. 2014;4(4):463-5.

12. Field T. Postpartum depression effects on early interactions, parenting and safety practices: a review. Infant Behav Dev. 2010;33(1):1-6.

13. Surkan PJ, Kennedy CE, Hurley KM, Black MM. Maternal depression and early childhood growth in developing countries :systematic review and meta analysis. Bull World Health Organ. 2011;89(8):608$15 \mathrm{D}$.

14. Stewart DE, Robertson E, Dennis CL, Grace SL, Wallington T. Postpartum depression: literature review of risk factors and interventions. Toronto:
University Health Network Women's health Program; 2003.

15. Dennis CL, Stewart DE. Treatment of postpartum depression, part 1: a critical review of biological interventions. J Clin Psychiatr. 2004;65(9):1242-51.

16. Dadi AF, Akalu TY, Baraki AG, Wolde HF. Epidemiology of post natal depression and its associated factors in Africa: A systematic review and meta anlysis PLoS One. 2020;15(4);e0231940.

17. Rani R, Nandi N, Parmar SS, Rathore P. Prevalence and risk factor analysis for post partum depression in women: a cross sectional study at tertiary care center. Int J Reprod Contracept Obstet Gynecol. 20209(1):266-9.

18. Azad R, Fahmi R, Shreshta S, Joshi H, Hasa M, Khan ANS. Prevalence and risk factors of postpartum depression within one yaer after birth in urban slums of Dhaka, Bangaldesh, PLoS ONE. 14(5):e0215735.

19. Kruthika K, Udayar SE, Mallapur MD. An epidemiological study of postnatal depression among women availing maternal health services in rural areas of Belgavi, Karnataka, India. Int J Community Med Public Health. 2017;4:759-63.

20. Hegde S, Latha KS, Bhat SM, Sharma PSVN, Kamth A. Postpartum Depression: Prevalence and Associated Factors among Women in Indian J Women Health Issues care. 2012;1:13-7.

21. D C Dutta's textbook of obstetrics, 9th edition.

Cite this article as: Kamath V, Ajila D, Shashirekha HD. Prevalence and risk factor analysis for postpartum depression: a cross sectional study at tertiary care center, Mangalore. Int J Reprod Contracept Obstet Gynecol 2021;10:988-92. 